\title{
An experimental investigation on the narrow annular-flow-induced vibration instability of a tube
}

\author{
H. S. Kang ${ }^{1}$, N. K. Muriethi ${ }^{2}$ \& M. J. Pettigrew ${ }^{2}$ \\ ${ }^{1}$ LWR Fuel Technology Division, \\ Korea Atomic Energy Research Institute, Korea \\ ${ }^{2}$ Department of Mechanical Engineering, \\ Ecole polytechnique de Montreal, Canada
}

\begin{abstract}
The stability of a simply-supported tube subjected to annular flow in a finitelength narrow gap support is experimentally investigated. The exit boundary condition of the annular-leakage passage is known to be a possible cause of instability of the inner tube. In this study, therefore, several finite-length gap supports considering two diffuser angles were investigated on the effects of the annular gap and diffuser angle to the instability of the inner tube. Numerous experiments with the different supports have been performed in a transparent plexiglass tube so that a basic annular-flow can be provided for the inner tube and the movement of the tube can be measured by several laser vibrometers. It is observed that (1) the tube loses stability by flutter at very low flow velocity; the highest critical flow velocity is $3 \mathrm{~m} / \mathrm{s}$, (2) the critical flow velocity is strongly dependent on the annular gap size, the diffuser angle and the combination of both, and (3) generally the smaller the gap the lower the critical flow velocity.

Keywords: instability, axial-flow-induced vibration, annular flow, finite-length narrow gap support, leakage flow.
\end{abstract}

\section{Introduction}

Several methods to predict the dynamic behavior of the rod subjected to an annular flow have been developed, These include the linearized potential flow theory based model by Mateescu and Paidoussis [1,2] and Mateescu et al. [3], 
and the pressure-loss models by Hobson [4], Fujita et al. [5] and Langthjem et al. [6]. Recently, Kang et al. proposed a theory based on the pressure-loss model with consideration of flow friction [7]. They showed the critical flow velocity of a simply-supported cylinder could go down to dimensionless velocity of 2.4. The basic dynamics due to annular flow are known by virtue of these models.

Mulcahy reported that a cantilevered tube conveying water showed selfexcitation by leakage flow through a slip joint [8]. Interestingly, he found that a limit cycle is attained below the flow rate at which the tube hit the wall, and at high flow rate the unstable motion switched to predominately second-mode motion from first-mode.

Although the analytical models were developed, to solve industrial problems such as heat exchanger tube and control rod vibrations in gas and water cooled reactors, the practical conditions provided by the tube-support plate geometry should be considered. For heat exchanger tubes, the support causes highly confined annular flow with a divergent or convergent flow at the exit or the entrance of the support, which was due to chamfering of the support hole for manufacturing convenience..

Gorman et al. qualitatively reported that a finite-length diffuser caused the thimble tube in a pressurized water reactor to reach dynamic instability [9]. In the study, a diffuser nozzle, straight hole nozzle and split square nozzle which has four vertical radial grooves were utilized. He found that large vibrations occurred with the diffuser nozzle.

Yasuo and Paidoussis tried to solve the flow-induced instability problem of heat exchanger tubes subjected to axial flow in a diffuser-shaped, loose intermediate support [10]. In their study, a diffuser exit of the intermediate support and potential flow theory considered together with a one-mode approximation of the inner tube. They suggested critical flow velocity equations either for divergence and flutter. Application of this theory to practical problems was, however, limited because of the inaccurate prediction of the critical flow velocity for flutter.

The purpose of this study is to obtain experimentally the critical flow velocity of a cylinder subjected to annular flow in a finite-length narrow-gap support at the middle of the cylinder and to identify instability.

\section{Experimental setup}

The test section with associated instrumentations is schematically shown in Figure 1.

Experiments were conducted in a $2.5 \mathrm{~m}$ long test section in which the flow rate ranged up to flow velocity of $12 \mathrm{~m} / \mathrm{s}$. A $2.2 \mathrm{~m}$ long and $15.9 \mathrm{~mm}(0.627$ inch) diameter inner tube was used with a finite-length narrow-gap support having a length of $38.7 \mathrm{~mm}$ (1.525 inch). The inner tube was supported by four pins at one end, therefore, a total of eight contact points for both ends to simulate pinned-pinned boundary conditions. The gaps between the inner tube and supports were $0.29 \mathrm{~mm}, 0.42 \mathrm{~mm}, 0.67 \mathrm{~mm}, 2.2 \mathrm{~mm}$, and the annular gap 


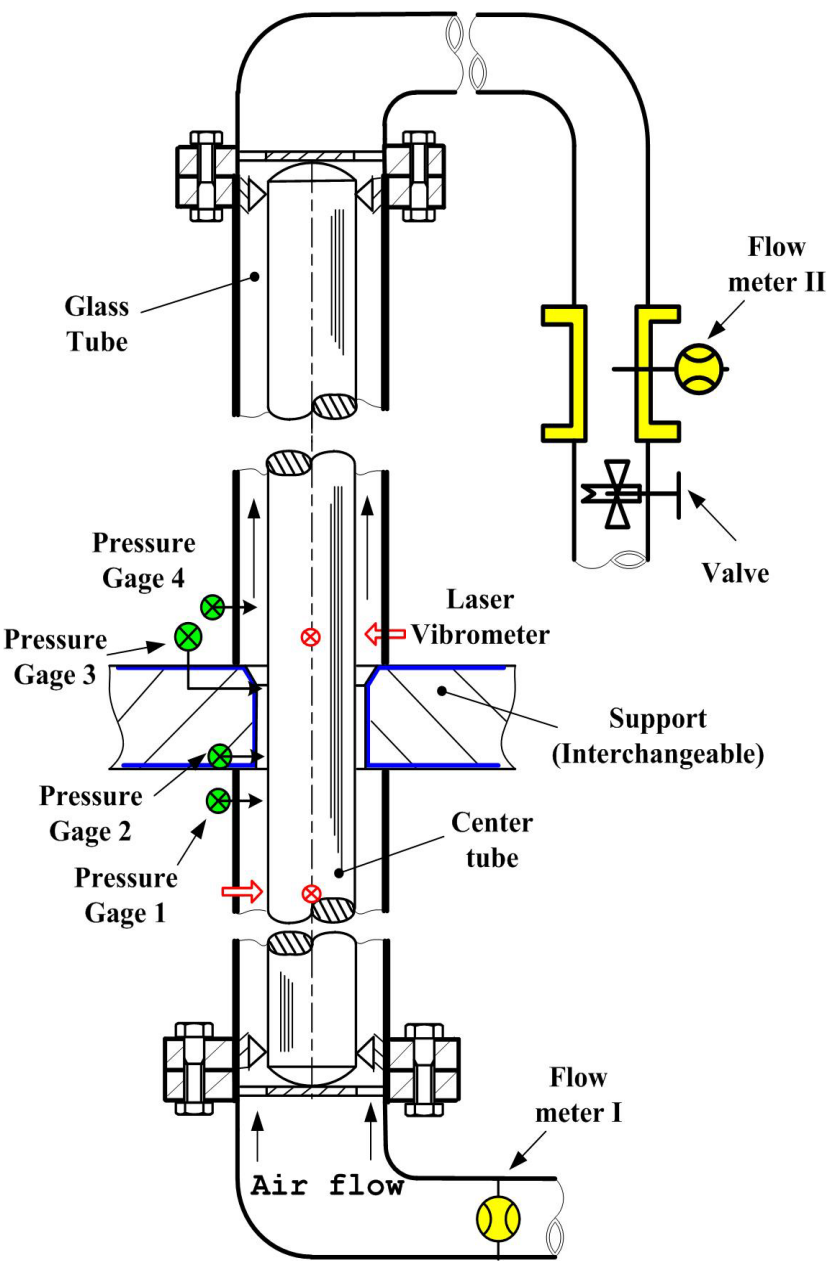

Figure 1: $\quad$ Schematic drawing of the test section and instruments.

between the inner tube and outer plexiglass tube is $5.15 \mathrm{~mm}$. Diffuser angles of $10^{\circ}$ and $20^{\circ}$ were provided at the downstream end of the support. All dimensions are summarized in Table 1.

Fluid parameters and vibration characteristics of the inner cylinder are summarized in Table 2 .

Compressed air comes into the test loop through a pressure regulator connected to the building services air supply. The air meets a contraction at the entrance to the test section due to the tube support, enters the annulus provided by the lower glass tube, and then, flows into the much smaller annular channel provided by the replaceable support. The air flow is controlled by a valve at the end of the test loop, so that higher flow velocities can be obtained by opening the valve. 
Table 1: $\quad$ Major dimensions of test apparatus.

\begin{tabular}{|c|c|}
\hline Item & Dimension \\
\hline \multirow{3}{*}{ Inner Cylinder } & Inner diameter: $14.15 \mathrm{~mm}$ \\
& Outer diameter: $15.93 \mathrm{~mm}$ \\
Length: $2.2 \mathrm{~m}$ \\
Young's modulus: $266.1 \mathrm{~N} / \mathrm{m}^{2}$ \\
\hline \multirow{3}{*}{ Outer glass tube } & Inner diameter: $26.24 \mathrm{~mm}$ \\
& Gap: $5.16 \mathrm{~mm}$ \\
\hline Support & Length: $38.1 \mathrm{~mm}$ \\
& Inner diameter $($ gap): \\
& (a) $16.51 \mathrm{~mm}(0.29 \mathrm{~mm})$ \\
(b) $16.76 \mathrm{~mm}(0.42 \mathrm{~mm})$ \\
(c) $17.27 \mathrm{~mm}(0.67 \mathrm{~mm})$ \\
(d) $20.32 \mathrm{~mm}(2.2 \mathrm{~mm})$ \\
& Diffuser angle: $10^{\circ}$ and $20^{\circ}$ \\
\hline
\end{tabular}

Table 2: Fluid parameters and vibration characteristics of the inside cylinder.

\begin{tabular}{|c|c|}
\hline Item & Dimension \\
\hline Fluid & $\begin{array}{r}\text { (a) compressed air }: \sim 100 \mathrm{psig} \\
\text { (b) density: } \sim 8.5 \mathrm{~kg} / \mathrm{m}^{3}\end{array}$ \\
\hline $\begin{array}{c}\text { Hydraulic dia. }(\mathrm{mm}) \text { at } \\
\text { support }\left(L / D_{h}\right)\end{array}$ & $\begin{array}{c}\text { (a) } 16.51 \text { support: } 0.58 \mathrm{~mm}(50) \\
\text { (b) } 16.76 \text { support: } 0.84 \mathrm{~mm}(34.8) \\
\text { (c) } 17.27 \text { support: } 1.35 \mathrm{~mm}(21.7) \\
\text { (d) } 20.32 \text { support }: 4.39 \mathrm{~mm}(6.6)\end{array}$ \\
\hline $\begin{array}{c}\text { Hydraulic dia. }(\mathrm{mm}) \text { at } \\
\text { glass tube }\left(L / D_{h}\right)\end{array}$ & $\begin{array}{c}10.31 \mathrm{~mm}(203.6) \\
\text { Natural frequency }(\mathrm{Hz}) \\
\text { without flow }\end{array}$ \\
\hline $\begin{array}{c}\text { Damping factor of the } \\
\text { inner cylinder }\end{array}$ & $\begin{array}{l}1^{\text {st }} \text { natural frequency: } 12.5 \\
3^{\text {rd }} \text { natural frequency: } 40.2 \\
4^{\text {th }} \text { natural frequency: } 150.2\end{array}$ \\
\hline $\begin{array}{c}\zeta_{1 s t} \\
=0.2 \% \text { for the } 1^{\text {st }} \text { natural frequency }\end{array}$ \\
\hline
\end{tabular}

As seen in Figure 1, vibration amplitudes are measured with four laser sensors (reflex sensor, Wenglor Company), in two directions near the support, at mid-span and at the one-fourth position along the test section. The measurement signals were acquired and analyzed using an Oros data acquisition system. 


\section{Experimental results and discussion}

The vibration amplitudes for different gaps and diffuser angles as functions of flow velocity are shown in Figure 2.
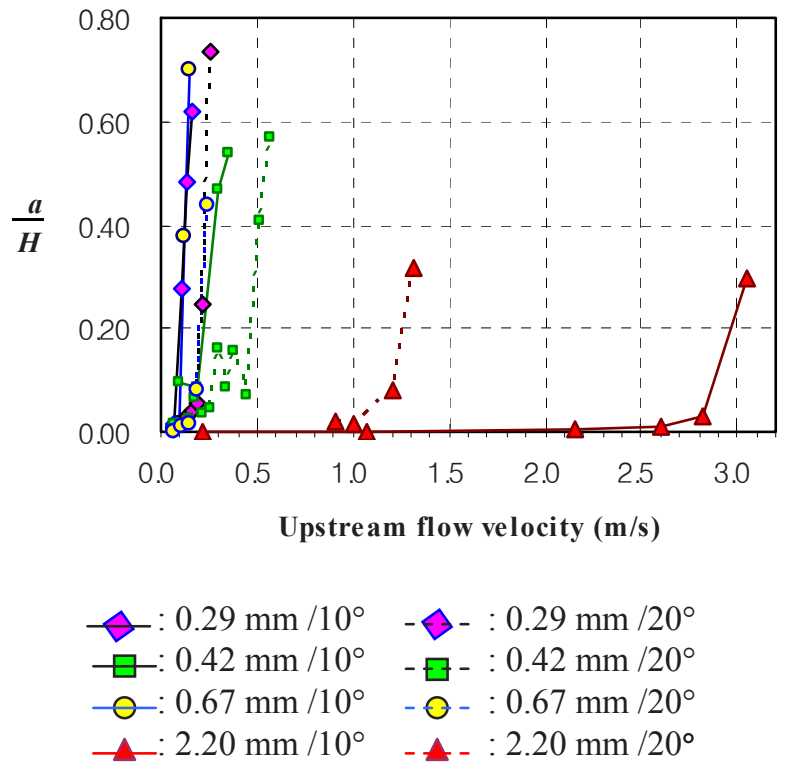

Figure 2: $\quad$ RMS amplitude of the inner cylinder as a function of flow velocity upstream of the support for different support gaps.

The lowest critical flow velocity of $0.10 \mathrm{~m} / \mathrm{s}$ (equivalent to $2.38 \mathrm{~m} / \mathrm{s}$ or 790 Reynolds number at the support) is obtained with the support having a $0.29 \mathrm{~mm}$ gap and a $10^{\circ}$ diffuser while the highest critical flow velocity of $2.82 \mathrm{~m} / \mathrm{s}$ (equivalent to $7.6 \mathrm{~m} / \mathrm{s}$ or 17,000 Reynolds number at the support) is observed with a $2.20 \mathrm{~mm}$ gap and a $10^{\circ}$ diffuser. Generally speaking, the smaller the gap and the diffuser angle the lower the critical flow velocity. However, for the 0.68 $\mathrm{mm}$ gap support, the critical flow velocity of $0.12 \mathrm{~m} / \mathrm{s}$ is obtained with the $10^{\circ}$ diffuser, which is significantly lower than that of the $0.42 \mathrm{~mm}$ gap support. The upstream critical flow velocity of $0.12 \mathrm{~m} / \mathrm{s}$ is equivalent to $1.14 \mathrm{~m} / \mathrm{s}$ or 870 Reynolds number at the support. For the largest gap $(2.2 \mathrm{~mm})$ support, interestingly, the critical flow velocity of the $20^{\circ}$ support is much lower. Critical flow velocities for all the supports are summarized in Table 3.

Figure 3 shows the measured $r m s$ vibration amplitude and damping factor as functions of the upstream flow velocity for the support having a $0.29 \mathrm{~mm}$ gap with a $20^{\circ}$ diffuser angle. The vibration amplitude starts increasing rapidly from $0.2 \mathrm{~m} / \mathrm{s}$. At the same time, the damping ratio has decreased to nearly zero. Then, as the inner cylinder starts impacting the support, the amplitude decreases while the "effective" damping ratio increases. The damping ratio is estimated by curve 
fitting the response spectrum in the neighborhood of the first mode frequency. All measurements for the different support geometries show the same trend as in Figure 3.

Table 3: $\quad$ Critical flow velocities for different supports.

\begin{tabular}{|c|c|}
\hline Support & $\begin{array}{c}\text { Critical flow velocity at } \\
\text { the upstream }(\mathrm{m} / \mathrm{s})\end{array}$ \\
\hline $0.29 \mathrm{~mm}$ gap with $10^{\circ}$ & 0.10 \\
$0.29 \mathrm{~mm}$ gap with $20^{\circ}$ & 0.19 \\
\hline $0.42 \mathrm{~mm}$ gap with $10^{\circ}$ & 0.22 \\
$0.42 \mathrm{~mm}$ gap with $20^{\circ}$ & 0.45 \\
\hline $0.67 \mathrm{~mm}$ gap with $10^{\circ}$ & 0.12 \\
$0.67 \mathrm{~mm}$ gap with $20^{\circ}$ & 0.20 \\
\hline $2.2 \mathrm{~mm}$ gap with $10^{\circ}$ & 2.82 \\
$2.2 \mathrm{~mm}$ gap with $20^{\circ}$ & 1.21 \\
\hline
\end{tabular}

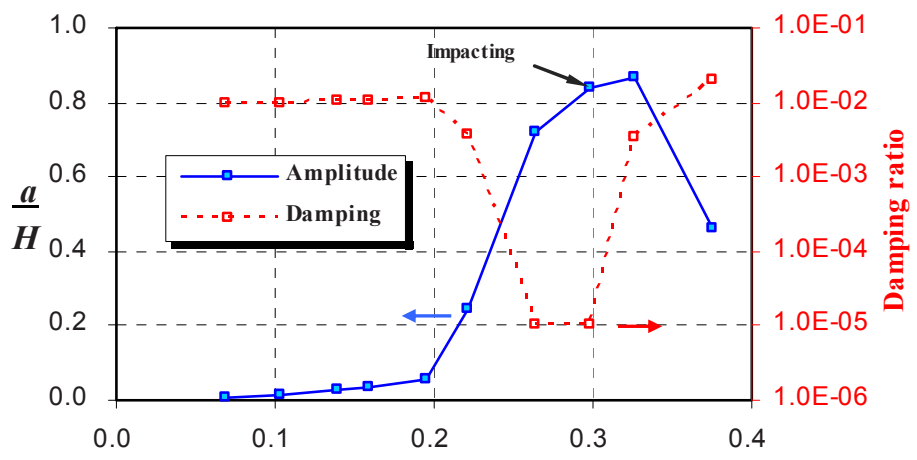

Ups tream Flow Velocity $(\mathrm{m} / \mathrm{s})$

Figure 3: Vibration amplitude and damping ratio as a function of upstream flow velocity for the inside cylinder in the support with $0.29 \mathrm{~mm}$ gap and $20^{\circ}$ diffuser angle.

While the vibration amplitude and the damping change, the natural frequency of the cylinder does not change at all before the onset of impacting, as shown in Figure 4. The $12.5 \mathrm{~Hz}$ and $40.2 \mathrm{~Hz}$ components are, respectively, the first and the second natural frequencies. When the inner cylinder starts impacting, the first natural frequency increases to $14.5 \mathrm{~Hz}$. Physically impacting increases the effective stiffness of the tube. 


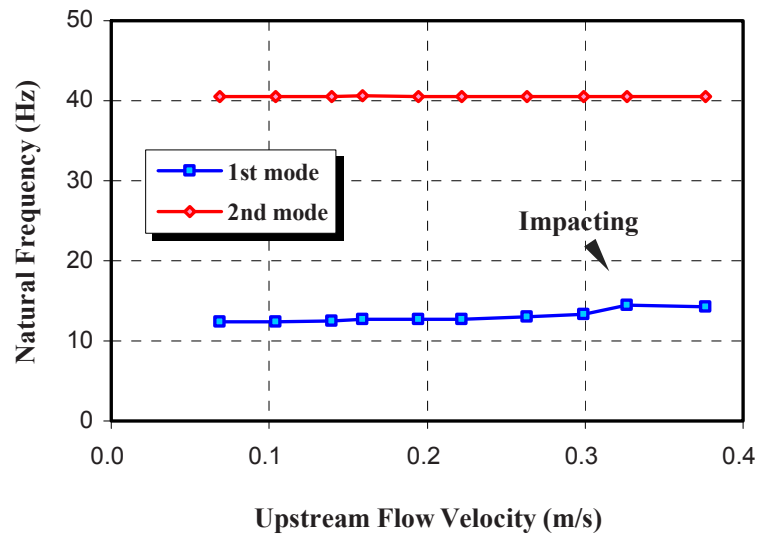

Figure 4: The first and the second natural frequencies as a function of upstream flow velocity for the inside cylinder in the support with $0.29 \mathrm{~mm}$ gap and $20^{\circ}$ diffuser angle.

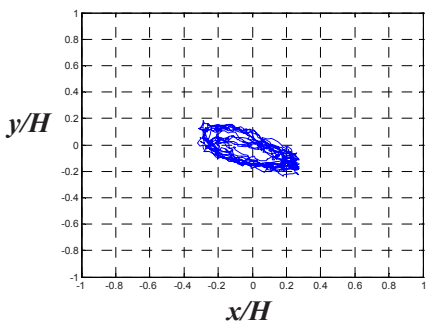

(a)

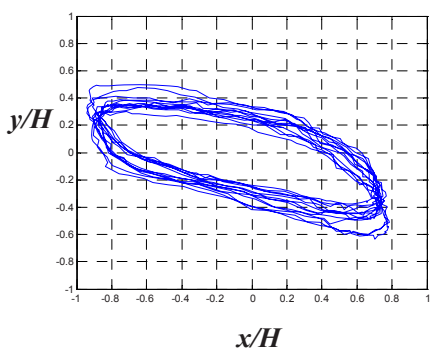

(c)

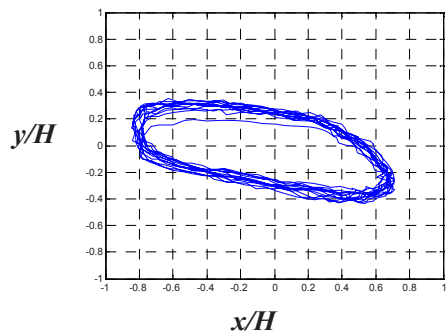

(b)

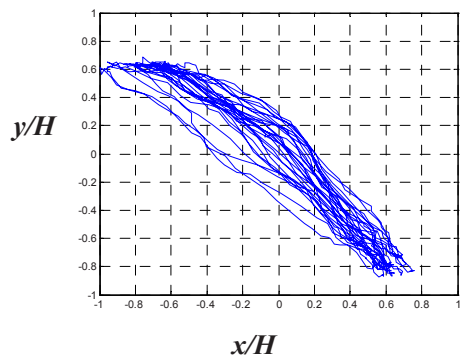

(d)

Figure 5: $\quad \mathrm{X}-\mathrm{Y}$ plots for the vibration of the inner cylinder in the support with $0.29 \mathrm{~mm}$ gap and $20^{\circ}$ diffuser angle. Upstream velocity (Reynolds numbers): (a) $0.22 \mathrm{~m} / \mathrm{s}(1,682)$, (b) $0.26 \mathrm{~m} / \mathrm{s}(1,994)$, (c) $0.30 \mathrm{~m} / \mathrm{s}$ $(2,262)$, (d) $0.38 \mathrm{~m} / \mathrm{s}(2,843)$. 
Figure 5 shows X-Y plots of the cylinder motion at the support elevation. As the amplitude increases, whirling motions are clearly observed, which is believed to be a limit cycle. It is well known that the limit cycle is the result of a dynamic instability. Once impacting starts, the limit cycle disappears. When the cylinder contacts the support, the cylinder seems to vibrate in a one-dimensional motion. This is a very typical vibration behavior for all the supports with increasing flow velocity.

The inner pinned-pinned cylinder loses its first mode stability at very low flow velocity for all support cases. The first instability is clearly observed in the first mode. The instability is believed to be a dynamic instability, not a static one. The reasons are:

(1) The critical flow velocity is too low to overwhelm the stiffness of the steel cylinder by negative fluid stiffness if any, which are summarized in Table 3 and shown in Figure 2.

(2) The natural frequencies do not change before the inner cylinder starts impacting the support, which is shown in Figure 4.

(3) Limit cycles are clearly observed for all the supports near the critical flow velocities one of which is shown in Figure 5,

(4) At a certain flow velocity where the vibration amplitude increases rapidly, the damping ratio starts decreasing drastically, which is shown in Figure 3.

\section{Conclusions}

The stability behavior of a pinned-pinned flexible rod subjected to narrow annular flow over a finite-length gap support has been experimentally studied. At significantly low air flow, flutter instability is observed for all supports; independently of the gap size and diffuser angle. With annular flow, the simply supported cylinder is known to lose stability by divergence at very high flow velocity beyond practical engineering applications. Interestingly, a small support plays a significant role to change the dynamic behavior of the pinned-pinned rod, decreasing the critical flow velocities down to engineering flow velocities. Generally speaking, the smaller gaps and the smaller diffuser angles lower the critical flow velocity for negative damping. On the other hand, for the largest gap $(2.20 \mathrm{~mm})$, the critical flow velocity of the larger diffuser angle $\left(20^{\circ}\right)$ is lower than that of the smaller diffuser angle $\left(10^{\circ}\right)$.

Further studies to unveil the basic mechanism behind the instability shown by this study are highly recommended for the heat exchanger tube within the tube support plate.

\section{References}

[1] Mateescu, D. and Paidoussis, M.P, 1985, The unsteady potential flow in axially variable annulus and its effect on the dynamics of oscillating rigid centre-body, J. of Fluid Engineering, 107, 421-427. 
[2] Mateescu, D. and Paidoussis, M.P, 1987, Unsteady viscous effects on the annular-flow-induced instabilities of rigid cylindrical body in narrow duct, J. of Fluids and Structures, 1, 197-215.

[3] Mateescu, D., Paidoussis, M.P and Sim, W. G., 1988, Dynamics and Stability of a flexible cylinder in a narrow coaxial cylindrical duct, subjected to annular flow, International Symposium on Flow-Induced Vibration and Noise, ASME, Nov. 27-Dec. 2. 125-145 Chicago, Illinois.

[4] Hobson, D.E., 1982, Fluid-elastic instabilities caused by flow in an annulus, Proceeding of BNES, 3rd international conference on vibration in nuclear plant, 440-460. Keswick, U.K.

[5] Fujita, K, Ito, T. Kawata, Y and Izumi, H., 1994. Axial leakage-flowinduced vibration of a long flexible rod with small gaps, Flow-Induced Vibration, ASME, PVP-Vol. 273, pp.133-143.

[6] Langthjem, M. A., Morita, H. Nakamura, T. and Nakano, M., 2006, A flexible rod in annular leakage flow: Influence of turbulence and equilibrium offset, and analysis of instability mechanism, J. of Fluids and Structures, 22 617-645.

[7] Kang, H. S., Mureithi, W. N and Pettigrew, M. J., analytical solution for a vibrating simply-supported cylinder subjected to 2-D concentric annular flow considering friction, J. of Fluids and Structures (Accepted).

[8] Mulcahy, T.M., 1988. One-dimensional leakage-flow vibration instabilities, J. of Fluids and Structures, 2, pp.383-403.

[9] Gorman, D. J., Goden, J.L. and Planchard, J., 1987. Analytical and Experimental Study of the Vibratory Response of a Flexible Tube Subjected External Annular Flow, Part way along its Length, Proceedings of International Conference on Flow-Induced Vibrations, ed., R. King, Bowness-on-Windermere, U.K., 1987, pp. 339-347.

[10] Yasuo, A. and Paidoussis, M. P., 1989. Flow-Induced Instability of HeatExchanger Tubes due to Axial flow in a Diffuser-shaped, Loose Intermediate Support, J. of Pressure Vessel Technology, 111, pp.428-434. 